\title{
A extensão do 'agro' e do tóxico: saúdee ambiente na terra indígena Marãiwatsédé, Mato Grosso
}

\section{The extension of 'agro' and toxic: the health and environmental in indigenous land Marãiwatsédé, Mato Grosso}

\author{
Francco Antonio Neri de Souza e Lima ${ }^{1,2 *}$ (D), Wanderlei Antonio Pignati ${ }^{1}$ (D), \\ Marta Gislene Pignatti ${ }^{1}$ (D) \\ ${ }^{1}$ Núcleo de Estudos Ambientais e Saúde do Trabalhador, Instituto de Saúde Coletiva, Universidade Federal de Mato Grosso \\ (UFMT) - Cuiabá (MT), Brasil. \\ ${ }^{2}$ Escola Nacional de Saúde Pública, Fundação Oswaldo Cruz (Fiocruz) - Rio de Janeiro (RJ), Brasil
}

Como citar: Lima FANS, Pignati WA, Pignatti MG. A extensão do 'agro' e do tóxico: saúde e ambiente na terra indígena Marãiwatsédé, Mato Grosso. Cad Saúde Colet, 2020;28(1):1-11. https://doi.org/10.1590/1414-462X202000280442

\section{Resumo}

Introdução: As monoculturas agrícolas são relacionadas ao uso de agrotóxicos, que poluem o ambiente e as pessoas, de regiões agrícolas. No nordeste do estado de Mato Grosso, a Terra Indígena (TI) Marãiwatsédé, território da etnia Xavante foi ocupada na década de 1950 por não-indígenas e teve seu ambiente modificado pela agropecuária até a desintrusão em 2012. Quando os Xavante retornaram para seu território, uma denúncia de óbitos infantis por suspeita de poluição da água por agrotóxicos motivou este estudo. Objetivo: Verificar resíduos de agrotóxicos na água e discutir a dinâmica de inserção da agropecuária na TI e região. Método: Foi quantificada a área plantada, o consumo de agrotóxicos, análises químicas na água e caracterizado o ambiente da TI e entorno. Resultados: A área plantada e o consumo de agrotóxicos da região da TI aumentou anualmente. Foi detectado resíduo de 0,19 $\mu \mathrm{g} / \mathrm{L}$ de permetrina na água. Havia lavouras em atividade nos limites da TI. Conclusão: Este valor está abaixo do Valor Máximo Permitido pela legislação brasileira, mas no limite da legislação europeia. No entanto, a presença de lavouras em atividade nos limites da TI são fontes constantes de emissão de agrotóxicos, possibilitando novas poluições de "fora para dentro" da TI.

Palavras-chave: agrotóxico; poluição da água; agronegócio; povos indígenas; Xavante.

\begin{abstract}
Background: Agricultural crops is directly relation to the use of pesticides, pollution the environment and people mainly from agricultural regions. The state of Mato Grosso, the indigenous land (IL) Marãiwatsédé, Xavante territory was occupied since 1950 by non-indigenous that environmental transformed by agricultural and farming until 2012. When the Xavante returns to Marãiwatsédé, denunciation of infant deaths by suspected pesticides water contamination motivated this study. Objective: To verify the residues of pesticides in the water and to discuss a dynamic of insertion of agriculture in the Marãiwatsédé and region. Method: It was quantified a planted area, pesticide consumption, realized chemical analysis in water and river sediment, and character environment this IL and surroundings. Results: Annually increase planted area in the region Marãiwatsédé with increase pesticide consumption. It was detected permethrin residue in the water at concentration to $0.19 \mu \mathrm{g} / \mathrm{L}$. There were crops in activity on the edge of IL. Conclusion: The permethrin found in water was levels were lower than the limit established by Brazilian legislation but like to Europe legislation, more restrictive. However, this crops in activity the edge Marãiwatsédé are continuous emission sources of pesticides, which allows new pollutions.
\end{abstract}

Keywords: pesticide; agrochemicals; agribusiness; water pollution; indigenous population.

Este é um artigo publicado em acesso aberto (Open Access) sob a licença Creative Commons Attribution, que permite uso, distribuição e reprodução em qualquer meio, sem restrições desde que o trabalho original seja corretamente citado.
Trabalho realizado na Terra indígena Marãiwatsédé, Mato Grosso, Brasil

Correspondência: Francco Antonio Neri de Souza e Lima. E-mail: franccoantonio@gmail.com

Fonte de financiamento: nenhuma.

Conflito de interesses: nada a declarar.

Recebido em: Set. 03, 2018. Aprovado em: Abril 14, 2019. 


\section{INTRODUÇÃO}

A questão do acesso à água é um direito humano reconhecido' e, apesar de estar em pauta na implantação das políticas públicas, as perspectivas da diminuição das poluições por produtos químicos (metais, desinfetantes, agrotóxicos, fertilizantes, etc.) continuam sombrias, principalmente as da água potável. Inúmeras substâncias têm sido processadas e lançadas ao ambiente pela indústria química para alavancar a produção agrícola e a indústria de transformação. Embora existam padrões de segurança para o uso, a forma como isto é feito tem causado contaminações ambientais e provocado agravos à saúde da população exposta ${ }^{2-4}$.

A presença de agrotóxicos no ambiente é uma preocupação para a saúde pública e seu monitoramento tem se tornado frequente. No ambiente, os recursos hídricos agem como integradores de processos biogeoquímicos e a presença dessas substâncias transformam matrizes ambientais (água, ar e alimentos) em vias de contaminação, aumentando a extensão de possíveis riscos sobre a saúde em locais muitas vezes distantes dos centros de utilização ${ }^{3,5}$.

No Brasil, os agrotóxicos são utilizados principalmente na agricultura voltada para exportação. Em Mato Grosso, no ano de 2012, nos 10,6 milhões de hectares plantados (somente para as culturas de soja, milho, algodão, cana-de-açúcar), foram consumidos aproximadamente 140,8 milhões de litros de agrotóxicos em produtos formulados, tornando o estado um dos maiores produtores agrícolas do país ${ }^{6}$, desde então. Este desempenho agrícola só é possível pelo uso de insumos como agrotóxicos e fertilizantes, o que torna o setor agrícola químico-dependente destas substâncias ${ }^{4}$. As consequências deste uso intenso de agrotóxicos têm sido detectadas em ambientes aquáticos, com mais frequência nas duas últimas décadas, em todo o mundo. As análises de água superficial parecem ser prioritárias, mas geralmente estão conciliadas com outros tipos de matrizes analisadas como água subterrânea, sedimento e bioindicadores, como anfíbios e peixes que apontam contaminações em uma escala não detectável por aparelhos, porque estão expostos constantemente no ambiente ${ }^{3}$. Essas poluições podem ocorrer por correntes aéreas através de pulverizações (por avião e trator) e infiltração no solo chegando até os lençóis freáticos, já sendo detectadas no ar, na chuva, na água e em animais ${ }^{3,7,8}$.

No Brasil, o Ministério da Saúde realiza um diagnóstico do monitoramento de agrotóxicos na água para consumo humano a partir das análises de dados do Sistema de Informação de Vigilância da Qualidade da Água para Consumo Humano (SisÁgua). Os dados de $2013^{9}$ mostram que 337 (21\%) municípios amostrados apresentaram algum resultado acima do Valor Máximo Permitido (VMP) com base na portaria de potabilidade da água MS no 2.914/2011 10 (PRC n 5 , de 28 de setembro de 2017, Anexo XX). No estado de Mato Grosso, foram investigados 38 municípios (26\%), dos quais, dez apresentaram parâmetros acima do VMP. Dentre estes princípios ativos, destacam-se aldrim/drieldrim, clordano, endrin, atrazina e DDT que totalizam 93,8\% das substâncias quantificadas no país.

Na saúde pública, as intoxicações agudas e crônicas por agrotóxicos passaram a ocupar lugar de destaque em eventos de exposição ambiental, ocupacional e alimentar ${ }^{4,6,11}$. As consequências da exposição frequente aos agrotóxicos trazem inúmeros agravos à saúde humana, podendo aumentar a taxa de mortalidade por malformações congênitas, na morbimortalidade por câncer infantojuvenil, distúrbios neurológicos associados a autismo, 12-14.

Historicamente a Terra Indígena (TI) Marãiwatsédé foi disputada desde a década de 1950 por indígenas e por não-indígenas (grileiros, posseiros, fazendeiros e políticos) ${ }^{15,16}$. Mesmo depois de demarcada, foi neste período que intensas apropriações ilegais de terras aconteceram transformando o ambiente natural em pastagens e lavouras. Este estudo agregou aspectos contextuais na perspectiva das mudanças socioambientais pela dinâmica do agronegócio, em curso na região; e o reflexo da produção agrícola, uso de agrotóxicos na região e as possíveis repercussões na saúde da população da TI. Este artigo trata das relações impositivas do agronegócio com as dinâmicas tradicionais socioambientais do povo Xavante da TI Marãiwatsédé, dos processos que levam ao adoecimento da população e da real possibilidade de poluição por agrotóxicos em seu território, como resultado das atividades agrícolas no entorno. 


\section{A Terra Indígena Marãiwatsédé}

Desde a década de 1940, a aproximação aos Xavante pelo Serviço de Proteção do Índio (SPI) não foi concluído pela interação com a comunidade Marãiwatsédé, que resistiram e não deixaram seu território ${ }^{17}$. Na década de 1960, colonizadoras sulistas e indústrias de pecuária receberam incentivos do governo militar para que investissem em fazendas de gado para exportação, principalmente no leste de Mato Grosso, onde vivem os Xavante. Uma dessas fazendas era a Suiá-Missu que já possuiu área de 695.843 hectares na região de Marãiwatsédé. Com a instalação desta fazenda, os Xavante deste território foram deportados para a Missão Salesiana na TI São Marcos, 400 km ao sul, em aviões da Força Aérea Brasileira - FAB ${ }^{16-18}$. Posteriormente para requererem junto a FUNAI um atestado da inexistência de aldeamento indígena neste local.

Durante o período na TI São Marcos, na década de 1980, as lideranças de Marãiwatsédé começaram uma mobilização com o objetivo de retornar ao território original. Já na década de 1990, a TI Marãiwatsédé pertencia a uma multinacional italiana, controlada pela Agip do Brasil S/A que foi pressionada na Conferência de Meio Ambiente em 1992 (Eco 92) a devolver a TI Marãiwatsédé aos Xavante. No mesmo ano, a Fundação Nacional do Índio (FUNAI) inicia o processo de demarcação da $\mathrm{Tl}$, que, antes de ser regularizada, sofre invasões de não-indígenas, dificultando o retorno dos Xavante após sua legalização. Em 1998, a FUNAI reconhece e homologa a TI Marãiwatsédé que ainda enfrentou diversos recursos judiciais de manutenção de posse. Os invasores da TI conseguiram liminar da justiça, apoiados por políticos influentes da região $\mathrm{O}^{15,16,18}$ garantindo a permanência dentro da $\mathrm{Tl}$, que continuou sendo desmatada para atividades agropecuárias. Em 2012, um grupo Xavante ocupou e permaneceu em uma pequena parcela da TI próximo à rodovia BR-158, que a atravessa. No mesmo ano, uma decisão do Tribunal Regional Federal -1 a Região revogou a decisão anterior do mesmo tribunal, autorizando a desintrusão (medida legal de desocupação de não-indígenas). A desintrusão teve início em agosto de 2012 e foi planejada por uma equipe de trabalho interministerial do Governo Federal, sendo totalmente concluída em 2013 com a entrega do "Auto de desocupação final"16,19.

Durante o retorno total dos indígenas na TI em 2013, nenhuma avaliação sanitária e ambiental foi realizada. Neste processo de retorno e adaptação dos indígenas, uma denúncia de morte de quatro crianças indígenas, que ocorreram no final de 2012 e começo de 2013, com suspeita de intoxicação provocada por agrotóxicos na água motivou este estudo. Parte desta pesquisa foi solicitada pela FUNAI e Secretaria Especial da Saúde Indígena (SESAI) do Ministério da Saúde (MS) ao grupo de pesquisadores do Instituto de Saúde Coletiva (ISC) da Universidade Federal de Mato Grosso (UFMT).

\section{MÉTODO}

Este estudo utilizou-se de algumas etapas da avaliação de risco proposto por Veiga e Fernandes ${ }^{20}$, na tentativa de evidenciar as pressões na saúde humana sobre o uso de agrotóxicos, decorrente da produção agrícola e dinâmica do agronegócio na região. Como avaliação da exposição e as possíveis vias destas exposições aos agrotóxicos, foram determinadas medidas de quantificação ambiental estimada pela área plantada destinada às lavouras, consumo de agrotóxicos e análises químicas na água. Além dos relatos sobre as mudanças sociossanitárias-ambientais na $\mathrm{Tl}$, característica de territórios com presença/influência política e econômica do agronegócio.

O estudo foi realizado na TI Marãiwatsédé (Latitude $11^{\circ} 47^{\prime} 52^{\prime \prime}$ Sul, Longitude 510 39' 50" Oeste) com área de 165.241 hectares (ha) tradicionalmente ocupada por indígenas, onde atualmente se inserem os municípios de Alto Boa Vista, Bom Jesus do Araguaia e São Félix do Araguaia, na região nordeste do estado de Mato Grosso ${ }^{21}$, figura 1. A população era de aproximadamente 980 pessoas, segundo as lideranças indígenas que durante o estudo viviam em uma única aldeia, na porção sul da TI.

Dados da área plantada (em hectare), principais culturas agrícolas dos municípios e rebanho de bovinos (em cabeças) que abrangem a TI Marãiwatsédé foram obtidos no Sistema do Instituto Brasileiro de Geografia e Estatística de Recuperação Automática - SIDRA 22 . 


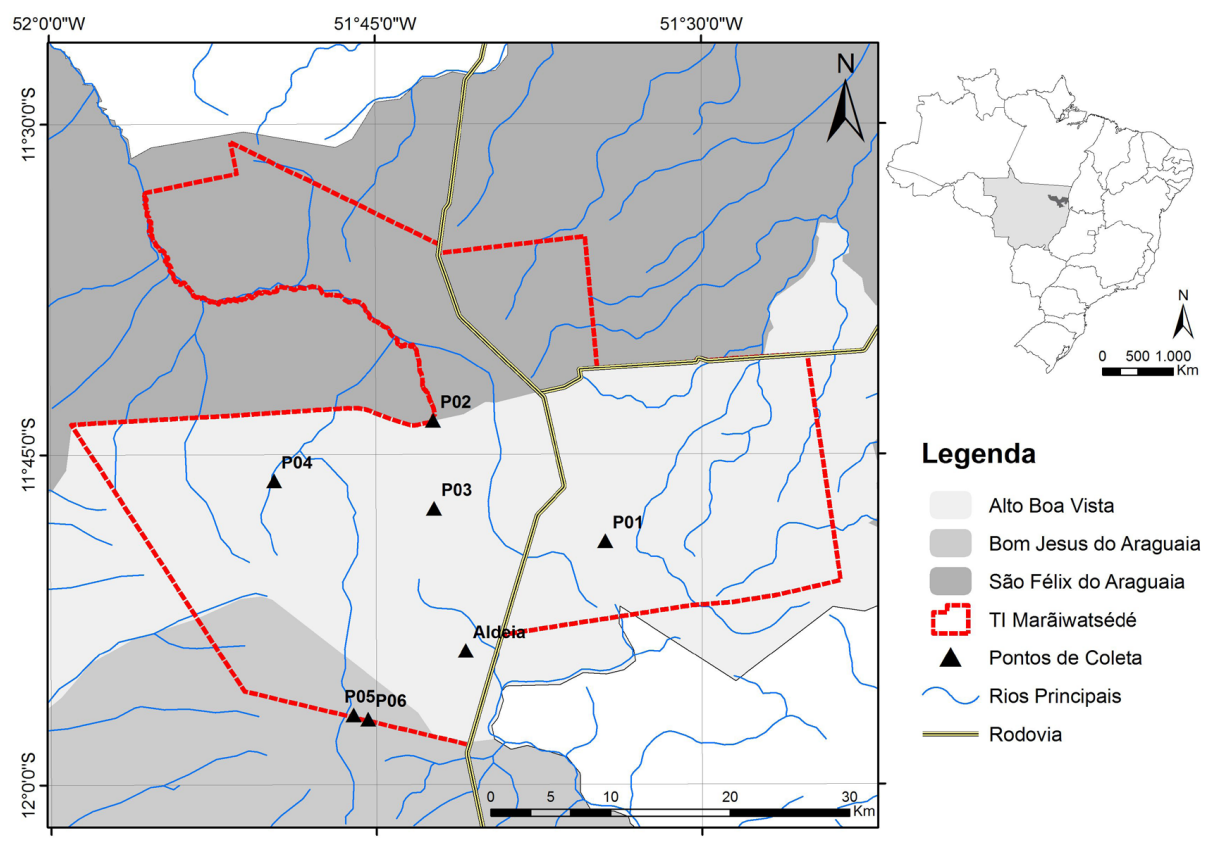

Figura 1. Imagem satélite da Terra Indígena Marãiwatsédé, pontos de coleta de água e sedimento e os três municípios limites, nordeste de Mato Grosso, Brasil.

As culturas agrícolas escolhidas foram arroz, milho e soja, comuns aos três municípios onde a TI está inserida. O levantamento da área plantada é utilizado porque fundamenta a possibilidade de contaminação no ambiente pelo uso de agrotóxicos utilizados nas lavouras. A série histórica apresentada foi de 2005 a 2012, um ano antes da desintrusão total da TI em 2013. Os tipos de agrotóxicos utilizados nesses três municípios foram obtidos no banco de dados do Instituto de Desenvolvimento Agropecuário de Mato Grosso - INDEA ${ }^{23}$. Este banco de dados eletrônico iniciado em 2005 era organizado através dos receituários agronômicos obrigatórios emitidos pelas revendedoras por meio de notas fiscais e contém informações como tipo de princípio ativo, volume dos agrotóxicos adquiridos e municípios utilizadores ${ }^{3,6}$.

Para estabelecer a média de consumo de agrotóxicos por hectare plantado, foram escolhidas as culturas de milho e soja porque representavam um consumo de aproximadamente $70 \%$ dos agrotóxicos comercializados em Mato Grosso ${ }^{6,24}$. Também foram estimados a quantidade de área plantada e o volume de agrotóxicos utilizados dentro da TI. Para isto, foi utilizada a porcentagem do município que é coberto pela TI, fornecida pelo Instituto Socioambiental ${ }^{21}$.

As análises laboratoriais para investigação de agrotóxicos na água e sedimento de rio foram realizadas no Laboratório de Análises de Resíduos de Biocidas do Departamento de Química da Universidade Federal de Mato Grosso (LARB/UFMT). Os procedimentos de amostragem e coletas seguiram diretrizes do Ministério da Saúde ${ }^{25}$ e Agência Nacional de Águas ${ }^{26}$.

A determinação dos locais de amostragem teve por base mapa hidrográfico, mapa satélite, com apoio de membros das coordenadorias da FUNAI, membros de ONGs atuantes na TI e lideranças indígenas, compostas pelos representantes da aldeia, geralmente homens adultos que tomam as decisões pela comunidade. Ao todo, foram amostrados sete pontos localizados na porção centro-sul da TI. Os pontos para amostragem de água e sedimento de rio foram escolhidos pela proximidade das lavouras com os limites da TI (Pontos P02, P05, P06), uso e interesses dos Xavante como aldeia (P08), construção de novas aldeias (P01, P04), local utilizado para alimentação como caça, pesca e coleta de frutos (P03). Realizou-se apenas uma coleta no mês de outubro de 2014, início das chuvas. 
As análises de água e sedimento foram feitas por Cromatografia Gasosa acoplada ao Espectrômetro de Massa (CG/EM) com doze padrões de agrotóxicos (pureza > 95,4\%). Os princípios ativos analisados foram: trifluralina, atrazina, metribuzin, malation, metolacloro, clorpirifos, endosulfan alfa, endosulfan beta, endosulfan sulfato, lambda cialotrina, permetrina e cipermetrina. Os padrões internos (fenantreno D-10 e terbutilazina) foram adquiridos das empresas Dr. Ehrenstorfer Gmbh (Augsburg, Germany), Sigma-Aldrich Laborchemikalien GmbH (Riedel-de-Haen) (Seelze, Germany) e Sigma-Aldrich Chemie GmbH (Steinheim, Germany). O CG (HP 6890) e EM (HP $5973 \mathrm{GmbH}$ ) foram equipados com amostrador automático (HP 7683), um injetor splitless (HP-5MS - 5\% Fenil metil siloxano) e uma coluna ( $30 \mathrm{~m} \times 250 \mu \mathrm{m}$ id $\times 0,25 \mathrm{~mm}$ de espessura do filme).

Os mapas foram elaborados no programa ArcGis 10.2 da Esri a partir de imagens satélites disponibilizadas pelo Instituto Nacional de Pesquisas Espaciais do Ministério da Ciência, Tecnologia, Inovações e Comunicações.

\section{RESULTADOS}

Ao percorrer a TI em três visitas, entre os anos de 2013 a 2015, foram visualizadas extensas áreas desmatadas, com presença de pasto e áreas de vegetação queimadas. Fluxo constante de carros e caminhões transportando grãos pela $\mathrm{Br}-158$, estrada que atravessa a Tl. Foram encontradas muitas embalagens de agrotóxicos, fertilizantes expostos no solo e um trator pulverizador, abandonado durante a desintrusão, com um tanque de aproximadamente 1000 litros com agrotóxico. Em áreas de construção de novas aldeias, que em alguns locais eram antigas sedes de fazenda, foram encontradas embalagens de agrotóxicos descartadas e sem armazenamento adequado. Montes de fertilizantes químicos também foram visualizados em várias áreas da TI e na aldeia Marãiwatsédé, próximo ao córrego.

Nos limites da TI, há lavouras em atividade localizadas na porção sul e centro (parte clara da imagem próxima aos pontos P02, P05, P06 - Figura 2) produzindo soja e milho próximo a cursos d'água que desembocam em locais utilizados para pesca dos Xavante (porção norte da TI a jusante do ponto P02). Na aldeia Marãiwatsédé, houve relatos de cheiro de agrotóxico

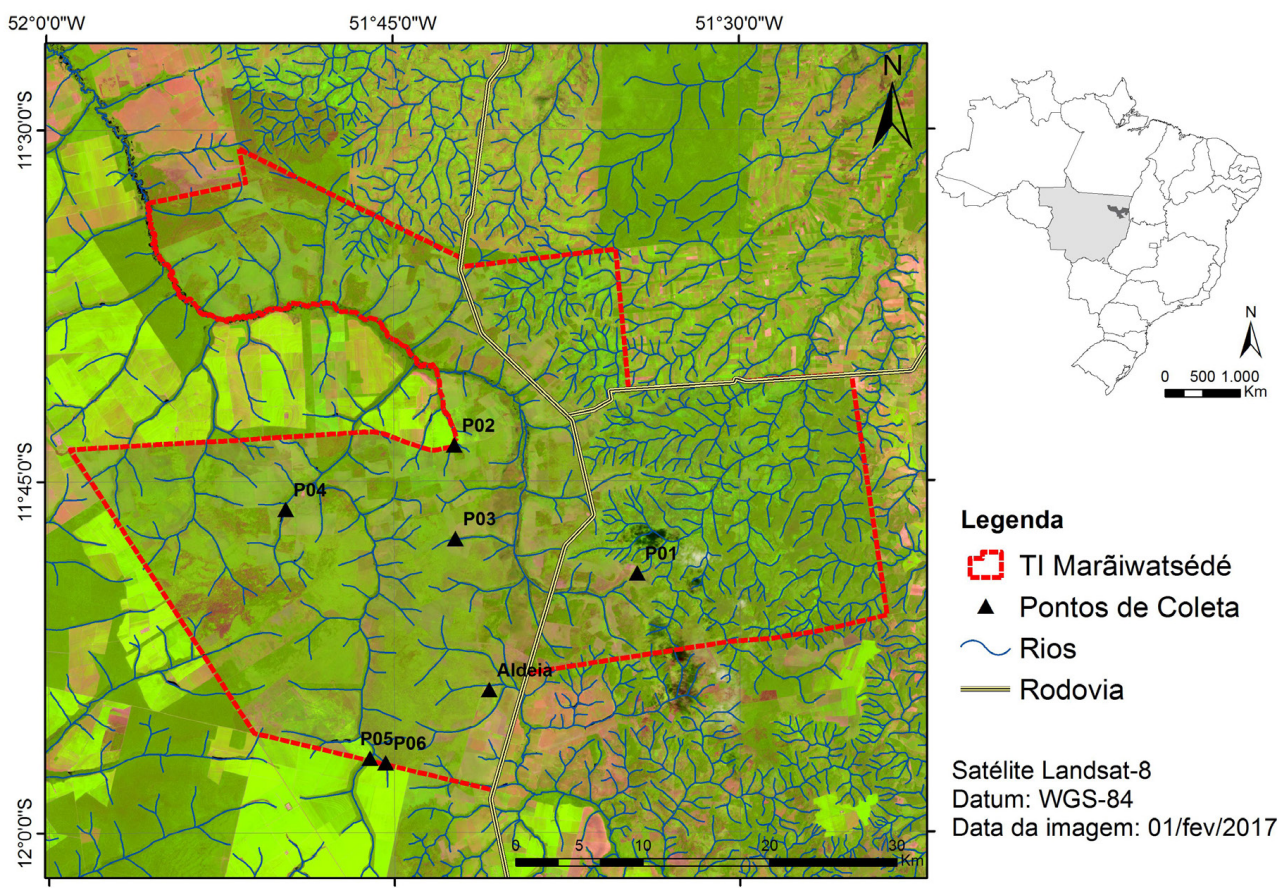

Figura 2. Imagem satélite da Terra Indígena Marãiwatsédé, pontos de coleta de água e sedimento, nordeste de Mato Grosso, Brasil. 
no ar e sintomas de garganta seca e tosse, que coincidem com período de atividade agrícola, mencionados desde a reunião realizada na aldeia junto com FUNAI, SESAI e ONGs em 2013. Essa pressão imposta aos moradores representa uma ameaça cotidiana e não mensurada na análise dos agrotóxicos na água e sedimento de rio. No entanto, enquanto dado empírico da realidade pesquisada, a análise da poluição reafirma esta pressão sentida e relatada pela população da TI.

O total de área plantada dos municípios do entorno da TI Marãiwatsédé foi de 166.501 hectares no ano de 2012 (Figura 3 A). Deste total de área plantada, cerca de 81\% (135.474 ha) foram destinados somente para cultura de soja. Estima-se que já foram plantados 9.227 ha de lavouras dentro da TI Marãiwatsédé. No entorno da TI, foram contabilizados 574.481 cabeças de gado no mesmo ano.

O consumo de agrotóxicos utilizados nos municípios da Tl, foi de aproximadamente 6,8 milhões de litros de agrotóxicos (produto formulado) entre os anos de 2005 a 2012, sendo estimado cerca de 296 mil litros na TI Marãiwatsédé (Figura 3-B). Para 2012, foram utilizados 2.2 milhões de litros de agrotóxicos no entorno, com estimativa de 106 mil em Marãiwatsédé.

A

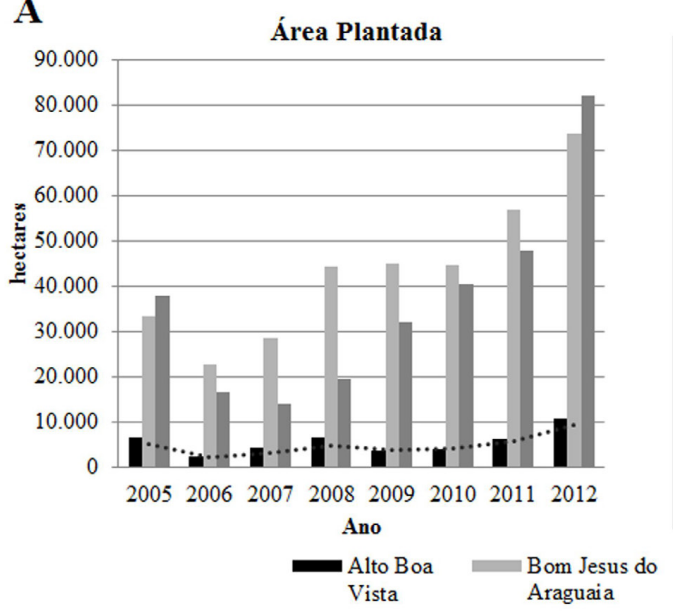

B

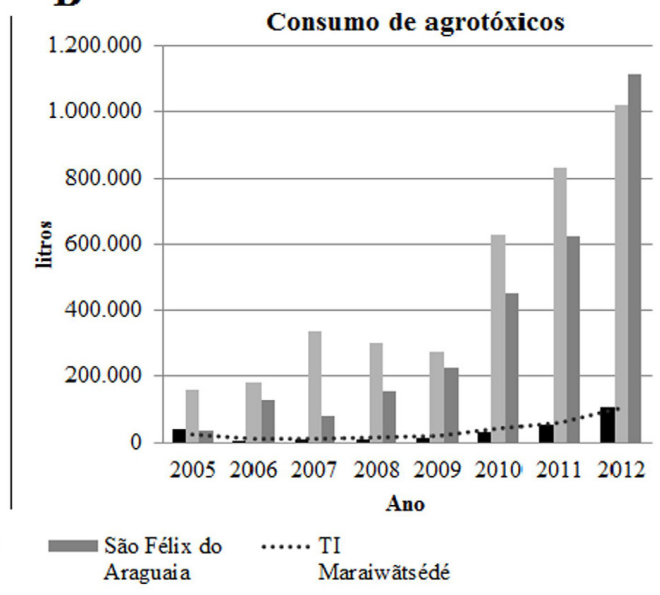

Figura 3. Área plantada (hectare)-A e consumo de agrotóxicos (litros)-B nos municípios do entorno e estimativa na Terra Indígena Marãiwatsédé, Mato Grosso, 2005 a 2012.

O consumo total de agrotóxicos, foram identificados 90 tipos de princípios ativos diferentes, na série história analisada, em que $21 \%$ eram extremamente tóxicos (Classe I), 24\% altamente tóxicos (Classe II), 35\% medianamente tóxicos (Classe III) e 18\% eram pouco tóxicos (Classe IV) na classificação para toxicidade humana. Sobre a classe dos produtos utilizados nessas lavouras, 39\% eram inseticidas, 37\% eram herbicidas, $16 \%$ fungicidas e $9 \%$ adjuvantes. Entre os dez agrotóxicos mais utilizados para o período estão Glifosato, 2,4-D e Atrazina (herbicidas); Metamidofós, Clorpirifos e Metomil (inseticidas); Carbendazim e Tebuconazol (Fungicidas); Óleo mineral e vegetal (adjuvantes).

Dos sete locais amostrados (figura 1), apenas um local apresentou resultado positivo para agrotóxicos na água. Foi detectado o princípio ativo permetrina na concentração de 0,19 $\mu \mathrm{g} / \mathrm{L}$ no ponto P01. Não houve detecção nos locais amostrados para sedimento de rio.

\section{DISCUSSÃO}

\section{As pressões e mudanças no território de Marãiwatsédé}

O mapa de Marãiwatsédé (Figura 2) mostra que alguns cursos d'água nascem fora dos limites da TI, passando por lavouras em atividade e se adentram nela. A vegetação foi desmatada para inserção da pecuária e lavoura, visualizado durante as visitas na TI e confirmando dados 
de Paret e Fanzeres ${ }^{18}$ que acrescentam que a redução das matas e cerrados foi de $37 \%$ da vegetação total, sendo $13 \%$ vegetação primária. As queimadas na TI são anuais, segundo dados do Instituto Nacional de Pesquisas Espaciais ${ }^{27}$, foram registrados 1.226 focos de queimada dentro de Marãiwatsédé em 2012. Em Mato Grosso, foram 172.814 focos de queimada, sendo 24.345 dentro de terras indígenas no mesmo ano. Parte destas queimadas são relatadas pelos indígenas como criminosa, porque estão em locais pouco visitados pelos Xavante. Isto gerou insegurança em percorrer o próprio território, ficando os Xavante impedidos de formar novas aldeias, o que ocasionou a concentração de pessoas em uma aldeia e a exploração rápida de alguns recursos como água, alimentos e materiais usados no cotidiano das famílias. Este cenário de desmatamento e queimada impacta diretamente a disponibilidade e soberania alimentar da população de Marãiwatsédé, que, segundo Maybury-lewis ${ }^{28}$, historicamente adquire parte de sua dieta alimentar por meio de caça, coleta de frutos e raízes. Deste modo, a população Xavante precisa de um ambiente com condições mínimas de conservação para compor sua dieta nutricional tradicional.

Desmatamento e queimadas são indicativos de atividades antrópicas que na TI representa disputas pelo território indígena, impulsionadas por dois motivos principais. O primeiro são as pressões políticas históricas (projetos de colonização do Estado, aliciamento de políticos locais e ligação com a agropecuária) que têm sido denunciadas pelos indígenas, por ONGs e instituições como o ministério público, que descobriu ligações entre os invasores da $\mathrm{TI}$ e políticos, em investigação junto à Polícia Federal ${ }^{15}$.

O segundo motivo apontado por Peres ${ }^{29}$, Leroy e Meirelles ${ }^{30}$, é econômico, por meio de expropriação de terras para inserção de pasto e lavouras. Os monocultivos são a hegemonia da agricultura destinada à exportação em uma economia globalizada, que para isso necessita de expansão de terras e adesão a um pacote tecnológico (agrotóxicos, fertilizantes, sementes transgênicas, créditos rurais). Para Leroy e Meirelles ${ }^{30}$, parte dessas pressões são de responsabilidade governamental que introduz a ideia de "progresso", como produtor de riqueza e salvador da miséria, como uma prioridade que não possa ser obstruída. Povos indígenas estão em posição contrária ao conceito econômico de "desenvolvimento" e seus costumes determinam a proporção do impacto sofrido. Essa afirmativa corrobora com Acselrad ${ }^{31}$ que caracteriza apropriação dos recursos naturais como uma forma de injustiça ambiental.

Para Pignati ${ }^{32}$, De Deus et al.$^{33}$, Leroy e Meirelles ${ }^{30}$, a agropecuária (associada à grilagem) é coerciva no processo "desenvolvimentista". Entre as práticas comuns estão manipulações cartoriais, violência, uso de poder público (executivo, legislativo, polícia), acompanhados de impactos ambientais (desmatamento, queimadas, uso de agrotóxicos), impactos na saúde humana (intoxicações agudas e crônicas, cânceres, malformações), impacto na cultura, como inserção de novos valores de consumo, preconceito, racismo e aliciamento. Este cenário para Porto e Schutz ${ }^{34}$ é de menor gestão democrática levando a consequências socioambientais e sanitárias de destruição dos ecossistemas, principalmente em culturas tradicionais, por ausência de políticas públicas e relação direta com interesses privados.

\section{Desempenho agrícola como produtor de vias de exposição}

A denúncia de óbitos infantis no período de 2012 a começo de 2013, com suspeita de intoxicação provocada por agrotóxicos na água pode ser interpretado de maneira geral como a identificação do perigo de contaminação da região. Corroborando Pignati ${ }^{6}$, em Mato Grosso, são identificadas quatro principais regiões de produção agrícola, sendo que a recente intensificação da produção se localiza nos municípios que compõem a bacia hidrográfica Xingu-Araguaia. Os três municípios estudados se localizam nesta quarta região de produção agrícola e seu desempenho produtivo (figura $3 \mathrm{~A}$ e B) analisada pelo crescimento da área plantada e consumo de agrotóxicos aumentou na série histórica verificada. A realidade sanitária-ambiental de municípios agrícolas deve variar com a quantidade e tipos de agrotóxicos utilizados. Porém, seus desfechos como intoxicações agudas e doenças crônicas devem ser semelhantes, por conta das vias de exposições e características tóxicas dos agrotóxicos. Deve-se ressaltar que populações tradicionais nestes territórios podem ser mais sensíveis a estas fontes de exposição a substâncias químicas, seja por seus hábitos ou por fatores genéticos. 
Segundo Nasrala-Neto et al. ${ }^{35}$, esse desempenho agrícola é motivo de atenção por trazer consequências negativas à saúde ambiental, afetando potencialmente a saúde das populações. Estas populações são afetadas pela referência à definição clássica "acidente químico ampliado" que é utilizada por Pignati ${ }^{32}$ como "acidente rural ampliado", definindo episódios ocupacional e/ou ambiental nas zonas rurais pelo uso de agrotóxicos nas lavouras, quando a intensidade do 'acidente' ultrapassa o local de produção. As consequências seriam prováveis contaminações destas substâncias no ar, água, solo, plantas, animais e população, com efeitos a longo prazo já citados neste estudo. Estas regiões de alto desempenho agrícola devem priorizar a implantação da Vigilância em Saúde de Populações Expostas a Agrotóxicos. Inserindo também as pressões dos monocultivos em territórios indígenas e os relatos destes povos na Promoção de Ações Específicas em Situações Especiais que compõe a Política Nacional de Atenção à Saúde Indígena ${ }^{36}$ e na Política Nacional de Saúde Integral das Populações do Campo, da Floresta e Águas.

\section{Quantificação da poluição como indicador de um processo de adoecimento}

A permetrina encontrada na amostra de água é um inseticida e formicida do grupo químico dos piretroides de tipo I, com classificação toxicológica classe III e é utilizada em culturas de algodão, arroz, couve, feijão, milho, soja, tomate e outros ${ }^{37,38}$. A toxicodinâmica acontece no Sistema Nervoso Central e periférico. A absorção por via oral é rápida por inalação e pode causar irritação de vias aéreas e reações de hipersensibilidade. A exposição à essa substância pode ocasionar irritação nos olhos e na pele, além de ter atividade neurotóxica, agir como desrregulador endócrino causando efeitos de reprodução e desenvolvimento. É tóxico em animais, insetos aquáticos e extremamente tóxico para abelhas ${ }^{37,39}$.

A concentração detectada de permetrina apresentada pela portaria de potabilidade da

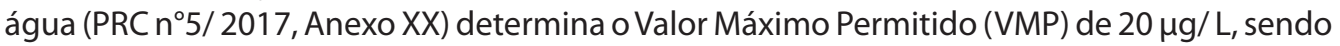
105 vezes maior do que o valor encontrado na amostra da TI. No entanto, para a legislação europeia ${ }^{40}$, permetrina é uma substância não autorizada para as culturas agrícolas desde o ano 2000 e seu VMP na água de consumo humano é de 0,1 $\mu \mathrm{g} / \mathrm{L}$. Esta diferença entre o valor permitido e não permitido ou do potável e não potável ultrapassa o cenário real da exposição populacional em que legislações voltadas para saúde e proteção das populações expostas no Brasil não conseguem alcançar. As decisões regulatórias saem do campo metodológico, técnico, acadêmico e se inserem nas questões político-econômicas. Países que mais utilizam estas substâncias, como o Brasil, tendem a manter suas legislações flexíveis (e permissivas às poluições intencionais) para substâncias de uso frequente, como ocorre com o herbicida glifosato que é o mais comercializado no mundo, cuja concentração é permitida no Brasil no valor de $500 \mu \mathrm{g} / \mathrm{L}$ na água (5000 vezes mais que na Comunidade Europeia).

Antes das análises de agrotóxicos serem concluídas, um quadro de diarreia (em alguns casos com presença de sangue) e mal-estar foi relatado pelos indígenas ao tomarem água da lagoa do ponto $P$ 01. A lagoa está em um local onde foi construída uma nova aldeia em que, antes da desintrusão, foram encontradas embalagens de agrotóxicos nas proximidades do poço de água, localizado nas proximidades da lagoa.

Os resultados das análises químicas da água confirmam as poluições ambientais e a possibilidade de exposição da população da TI. As concentrações variam de acordo com a quantidade lançada no ambiente que é utilizada nas lavouras, frequência de amostragem, técnica e capacidade analítica dos laboratórios de análise de água, conforme discutidos por Bonansea et al. ${ }^{41}$. A amostragem deste estudo foi reduzida de 15 para sete pontos devido à ameaça em percorrer o território no período pós-desintrusão, por recomendação da Polícia Federal e dos indígenas. Com isso, retiramos os pontos de amostragem na porção norte da TI. A baixa detecção de agrotóxicos investigada neste estudo pode estar relacionada com a capacidade analítica do laboratório (foram investigados apenas 12 tipos de agrotóxicos) e com frequência de amostragem que foi apenas de um período. Para além da evidencia técnica dos laudos laboratoriais, a presença dos agrotóxicos evidencia um modelo de apropriação ambiental praticado pelo agronegócio como oposto ao tradicionalmente praticado pelo povo 
Xavante, coletor-caçador. Com o consentimento do Estado, permite-se a instalação de fontes fixas de poluição, aqui as lavouras, que lançam essas substâncias constantemente no ambiente. A detecção ou não dos agrotóxicos começa a ter um significado simplista porque não consegue mensurar, de fato, outros efeitos secundários da presença das lavouras no entorno dos seus territórios, demarcados também por uma perspectiva sociocultural não-indígena.

As injustiças ambientais vivenciadas no cotidiano deste povo envolvem a dinâmica de uso da terra pelo agronegócio e inserção de agricultura e a poluição de sistemas hídricos que passam nas proximidades das lavouras e adentram as terras indígenas.

As pressões econômicas envolvendo práticas de aliciamento, arrendamento de terras, cooperação ilícita com agricultores, esgarçam um modo de vida baseado em outros valores de respeito à vida e costumes tradicionais que podem ser considerados como uma violação dos direitos humanos, à medida que impedem a reprodução do modo de vida tradicional do povo Xavante.

Como a área plantada das lavouras dos municípios da região da TI Marãiwatsédé aumenta anualmente e junto com ela o consumo de agrotóxicos (produção químico- dependente), ampliam-se também as fontes de emissão destas substâncias. Com base nos resultados deste estudo e pela dinâmica de produção econômica da região, sugere-se monitoramento ambiental permanente no interior e entorno da TI Marãiwatsédé, para queimadas, desmatamento e exposição aos agrotóxicos.

\section{AGRADECIMENTOS}

Os autores agradecem a toda comunidade Xavante da TI Marãiwatsédé pela participação e permissão na realização do estudo e à Operação Amazônia Nativa pelo fundamental apoio na execução do estudo.

\section{REFERÊNCIAS}

1. Castro E, Maria H, Morais P. O direito à água como política pública na América Latina. Brasília: Ipea; 2015. $322 \mathrm{p}$.

2. Curvo HRM, Pignati WA, Pignatti MG. Morbimortalidade por câncer infantojuvenil associada ao uso agrícola de agrotóxicos no Estado de Mato Grosso, Brasil. Cad Saúde Coletiva. 2013;21(1):10-7.

3. Moreira JC, Peres F, Simões AC, Pignati WA, Dores EDC, Vieira SN, et al. Contaminação de águas superficiais e de chuva por agrotóxicos em uma região do estado do Mato Grosso. Cien Saude Colet. 2012;17(6):155768. http://dx.doi.org/10.1590/S1413-81232012000600019. PMid:22699646.

4. Carneiro FF, Augusto LG S, Rigotto RM, Friedrich K, Búrigo AC. Dossiê ABRASCO: um alerta sobre os impactos dos agrotóxicos na saúde [Internet]. Rio de Janeiro: ABRASCO; 2015 [citado em 2015 abr 10]. p. 624 Available from: http://www.abrasco.org.br/site/wp-content/uploads/2015/03/Dossie_Abrasco_02. pdf\%5Cnhttp://linkinghub.elsevier.com/retrieve/pii/B9788445820667000033

5. Majewski MS, Coupe RH, Foreman WT, Capel PD. Pesticides in mississippi air and rain: A comparison between 1995 and 2007. Environ Toxicol Chem. 2014;33(6):1283-93. http://dx.doi.org/10.1002/etc.2550. PMid:24549493.

6. Pignati W, Oliveira NP, da Silva AMC. Vigilância aos agrotóxicos: quantificação do uso e previsão de impactos na saúde-trabalho-ambiente para os municípios brasileiros. Cien Saude Colet. 2014;19(12):4669-78. http:// dx.doi.org/10.1590/1413-812320141912.12762014. PMid:25388175.

7. Santos LG, Lourencetti C, Pinto AA, Pignati WA, Dores EF. Validation and application of an analytical method for determining pesticides in the gas phase of ambient air. J Environ Sci Health B. 2011;46(2):150-62. http://dx.doi.org/10.1080/03601234.2011.535381. PMid:21328123.

8. Hayes TB, Anderson LL, Beasley VR, De Solla SR, Iguchi T, Ingraham H, et al. Demasculinization and feminization of male gonads by atrazine: Consistent effects across vertebrate classes. J Steroid Biochem Mol Biol. 2011;127(1-2):64-73. http://dx.doi.org/10.1016/j.jsbmb.2011.03.015. PMid:21419222.

9. Brasil. Ministério da Saúde. Secretaria de Vigilância em Saúde. Monitoramento de Agrotóxicos na água para consumo humano no Brasil, 2013. Brasília; 2015. (Boletim Epidemiológico; 46).

10. Brasil. Ministério da Saúde. Portaria MS n²914, de 12 de dezembro de 2011. Dispõe sobre os procedimentos de controle e de vigilância da qualidade da água para consumo humano e seu padrão de potabilidade. Diário Oficial da União, Brasília, 14 de dezembro de 2011, Seção 1. p. 1-32. 
11. Araújo IMM, Oliveira ÂGRC. Agrotóxicos: impactos à saúde dos trabalhadores agrícolas no nordeste brasileiro. Trab Educ Saúde. 2017;15(1):117-29. http://dx.doi.org/10.1590/1981-7746-sol00043.

12. Shelton JF, Geraghty EM, Tancredi DJ, Delwiche LD, Schmidt RJ, Ritz B, et al. Neurodevelopmental disorders and prenatal residential proximity to agricultural pesticides: The charge study. Environ Health Perspect. 2014;122(10):1103-9. http://dx.doi.org/10.1289/ehp.1307044. PMid:24954055.

13. Oliveira NP, Moi GP, Atanaka-Santos M, Silva AMC, Pignati WA, Oliveira NP, et al. Malformações congênitas em municípios de grande utilização de agrotóxicos em Mato Grosso, Brasil. Cien Saude Colet. 2014;19(10):4123-30. http://dx.doi.org/10.1590/1413-812320141910.08512014. PMid:25272121.

14. Cremonese C, Freire C, Camargo AM, Lima JS, Koifman S, Meyer A. Pesticide consumption, central nervous system and cardiovascular congenital malformations in the South and Southeast region of Brazil. Int J Occup Med Environ Health. 2014;27(3):474-86. http://dx.doi.org/10.2478/s13382-014-0269-5. PMid:24847732.

15. Ministério Público Federal. MPF e PF deflagram operação contra invasores de terras indígenas [Internet]. 2014 [citado em 2015 maio 8]. Disponível em: https://mpf.jusbrasil.com.br/noticias/131551730/mpf-epf-deflagram-operacao-contra-invasores-de-terras-indigenas

16. Fundação Nacional do Índio. Esclarecimentos da Funai sobre o processo de desintrusão da Terra Indígena Marãiwatsédé, no Mato Grosso [Internet]. Brasília; 2012 [citado em 2013 out 14]. p. 2-4. Disponível em: http://www.funai.gov.br/index.php/comunicacao/noticias/1805-esclarecimentos-da-funai-sobre-oprocesso-de-desintrusao-da-terra-indigena-maraiwatsede-no-mato-grosso

17. Garfield S. Luta indígena no coração do Brasil. A Política indigenista, a marcha para o oeste e os índios xavante (1937-1988). São Paulo: UNESP; 2011. p. 416.

18. Paret CGP, Fanzeres A. Marãiwatsédé:Terra de Esperança [Internet]. Cuiabá: ANSAOPAN; 2012 [citado em 2013 out 14]. Disponível em: https://issuu.com/amazonianativa/docs/livro_xavante_web

19. Fundação Nacional do Índio. Concluída a desintrusão da Terra Indígena Marãiwatsédé (MT) [Internet]. Brasília: Funai; 2013 [citado em 2013 out 14]. Disponível em: http://www.funai.gov.br/index.php/ comunicacao/noticias/596-concluida-a-desintrusao-da-terra-indigena-maraiwatsede-mt

20. Veiga LHS, Fernandes HM. Avaliação de risco para a saúde humana e ecossistemas. In: Brilhante OM, Caldas LQA. Gestão e Avaliação de Risco em Saúde Ambiental. Rio de Janeiro: Editora FIOCRUZ; 1999. p. 155.

21. Instituto Socioambiental. Terras Indígenas [Internet]. 2015 [citado em 2015 abr 10]. Disponível em: http:// ti.socioambiental.org/pt-br/

22. Instituto Brasileiro de Geografia e Estatística. Sistema IBGE de Recuperação Automática. Produção Agrícola Municipal. Rio de Janeiro: IBGE; 2014.

23. Instituto de Defesa Agropecuária do Mato Grosso. Relatório/Planilha de Dados do Sistema de Informação de Agrotóxicos dos anos de 2005 a 2012. Cuiabá: Instituto de Defesa Agropecuária do Mato Grosso; 2013.

24. Bombardi LM. Agrotóxicos e agronegócio: arcaico e moderno se fundem no campo brasileiro. Uso de Agrotóxicos no Brasil [Internet]. 2012. p. 1-13. [citado em 2015 abr 10]. Disponível em: http://www. reformaagrariaemdados.org.br/biblioteca/artigo-e-ensaio/agrotóxicos-e-agronegócio-arcaico-emoderno-se-fundem-no-campo-brasileiro

25. Brasil. Ministério da Saúde. Secretaria de Vigilância em Saúde. Diretriz Nacional do Plano de Amostragem da Vigilância em Saúde Ambiental relacionada à qualidade da água para consumo humano [Internet]. Brasília; 2006 [citado em 2015 abr 10]. Disponível em:: www.saude.gov.br/svs

26. Companhia Ambiental do Estado de São Paulo. Guia nacional de coleta e preservação de amostras: água, sedimento, comunidades aquáticas e efluentes líquidos. São Paulo: CETESB; Brasília: ANA; 2011. p. 326.

27. Brasil. Ministério da Ciência, Tecnologia, Inovações e Comunicações. Instituto Nacional de Pesquisas Espaciais. Programa queimadas [Internet]. 2017 [citado em 2017 fev 4]. Disponível em: http://sigma. cptec.inpe.br/queimadas/index_old.php

28. Maybury-lewis D. A sociedade Xavante. Rio de Janeiro: Francisco Alves Editora S/A; 1984. 400 p.

29. Peres F. Saúde, trabalho e ambiente no meio rural brasileiro. Cien Saude Colet. 2009;14(6):1995-2004. http://dx.doi.org/10.1590/S1413-81232009000600007. PMid:20069168.

30. Leroy JP. Meirelles J. Povos indígenas e Comunidades tradicionais: os visados territórios dos invisíveis. In: Porto MF, Pacheco T, Leroy JP, editors. Injustiça ambiental e saúde no Brasil, o mapa dos conflitos. Rio de Janeiro: Editora FIOCRUZ; 2013. p. 115-31.

31. Acselrad H, Mello CCA, Bezerra GN. O que é justiça ambiental. Rio de Janeiro: Garamond; 2009. p. 160. 
32. Pignati WA. Os riscos, agravos e vigilância em saúde no espaço de desenvolvimento do agronegócio no Mato Grosso. Rio de Janeiro: Fundação Oswaldo Cruz, Escola Nacional de Saúde Pública Sergio Arouca; 2007.

33. Deus JAS, Rodrigues L M, Castro HM. Sociedades indígenas sitiadas pelo agribusiness na Amazônia meridional: uma abordagem etnopolítica dos processos de submissão ou resistência das comunidades tradicionais a tentativas de aliciamento e cooptação. In: Anais do $21^{\circ}$ Encontro Nacional de Geografia Agrária; 2012 outubro 15-19; Uberlândia. Uberlândia: Universidade Federal de Uberlândia; 2012. p. 1-13.

34. Porto MFS, Schütz GE. Gestão ambiental e democracia: análise crítica, cenários e desafios. Cien Saude Colet. 2012;17(6):1447-56. http://dx.doi.org/10.1590/S1413-81232012000600009. PMid:22699636.

35. Nasrala-Neto E, Lacaz FAC, Pignati WA. Vigilância em saúde e agronegócio: os impactos dos agrotóxicos na saúde e no ambiente. Perigo à vista! Cien Saude Colet. 2014;19(12):4709-18. PMid:25388179.

36. Brasil. Fundação Nacional de Saúde. Política Nacional de Atenção à Saúde dos Povos Indígenas. Brasília: FUNASA; 2002.

37. Itho SF. Rotina de atendimento do intoxicado. Vitória; 2007.

38. Agência Nacional de Vigilância Sanitária. Monografias de agrotóxicos: Permetrina [Internet]. Brasília; 2010 [citado em 2015 maio 14]. Disponível em: http://portal.anvisa.gov.br/documents/111215/117782/ P06-270910.pdf/65d99a2d-1393-4701-adc2-a63684e8b5b8

39. Pesticide Properties DataBase. Permethrin [Internet]. Reino Unido; 2014. Available from: http://sitem. herts.ac.uk/aeru/ppdb/en/Reports/515.htm\#3

40. The European Parlament and the Council of the European Union. Directiva 98/83/CE do Conselho de 3 de Novembro de 1998. Jornal Oficial das Comunidades Europeias; 1998. p. 32-54.

41. Bonansea RI, Amé MV, Wunderlin DA. Determination of priority pesticides in water samples combining SPE and SPME coupled to GC-MS. A case study: Suquía River basin (Argentina). Chemosphere. 2013;90(6):18609. http://dx.doi.org/10.1016/j.chemosphere.2012.10.007. PMid:23177716. 